\title{
Multiwalled Carbon Nanotube Nanofluids Used for Heat Dissipation in Hybrid Green Energy Systems
}

\author{
Yi-Hsuan Hung and Hung-Jhih Gu \\ Department of Industrial Education, National Taiwan Normal University, No. 162, Heping East Road, Section 1, \\ Da-an District, Taipei City 10610, Taiwan
}

Correspondence should be addressed to Yi-Hsuan Hung; hungyh@ntnu.edu.tw

Received 22 April 2014; Accepted 16 June 2014; Published 13 July 2014

Academic Editor: Chunyi Zhi

Copyright (C) 2014 Y.-H. Hung and H.-J. Gu. This is an open access article distributed under the Creative Commons Attribution License, which permits unrestricted use, distribution, and reproduction in any medium, provided the original work is properly cited.

\begin{abstract}
This study was conducted to characterize carbon nanotube (CNT)/water nanofluids (CNWNFs) and to apply the nanofluids in a heat-dissipation system of dual green energy sources. CNTs were mixed with water in weight fractions of $0.125 \%, 0.25 \%$, and $0.5 \%$ to produce nanofluids. The thermal conductivity, density, viscosity, and specific heat of the nanofluids were measured. An experimental platform consisting of a simulated dual energy source and a microchip controller was established to evaluate the heat-dissipation performance. Two indices, the heat dissipation enhancement ratio and specific heat dissipation enhancement ratio (SHDER), were defined and calculated. The CNWNFs with a CNT concentration of $0.125 \mathrm{wt} . \%$ were used because they exhibited the highest SHDER. The steady-state performance was evaluated at 2 flow rates, 11 hybrid flow ratios, and 3 heating ratios for a total power of $1000 \mathrm{~W}$. The transient behavior of the energy sources at preset optimal temperatures was examined, and the CNWNFs exhibited average increases in stability and heat dissipation efficiency of $36.2 \%$ and $5 \%$, respectively, compared with water. This nanofluid heat-dissipation system is expected to be integrated with real dual energy sources in the near future.
\end{abstract}

\section{Introduction}

Using green energy sources is critical for achieving zero emissions and environmentally clean zones worldwide. Hydrogen fuel cells and energy-storage devices such as lithium batteries and supercapacitors are considered promising future green energy sources because they do not cause pollution, their operational efficiency is high, and they can be developed sustainably [1]. Communications, household power module, transportation, and industrial applications urgently require green energy sources to meet stringent environmental regulations and government policies (key research areas and policies related to hydrogen energy are listed in [2]). Therefore, manufacturers and research institutes have developed several hydrogen fuel cell and battery prototypes, demonstration environments, and even commercial products. To compensate for the drawbacks of current green energy sources and maximize system output, a hybrid configuration has been applied widely $[3,4]$. For instance, in a proton exchange membrane fuel cell (PEMFC)/lithium battery hybrid system that was applied in electric vehicles, the PEMFC increased mileage, and the battery provided the substantial amount of power required [5]. In addition, several other combinations of batteries, supercapacitors, and PEMFC systems have been analyzed [6-9]. Appropriate system designs and well-controlled mechatronics can be used to enhance the performance of dual energy sources.

To manage green energy sources effectively, the operational temperature must be considered, because it strongly influences the efficiency, energy-storage capacity, life cycle, and peak output power of a system [10]. Therefore, a welldesigned heat-dissipation system is crucial for green energy sources. For hydrogen fuel cells, a thermal water management system was modeled using a lumped parameter technique, and the modeled parameters were compared with experimental results [11]. In addition, a cooling system for a $5 \mathrm{~kW}$ PEMFC was modeled and integrated with fuzzy control rules [12]. The temperature of the circulating coolant was controlled by regulating the coolant flux and the bypass valve to achieve the objective working range. The problems and 
challenges regarding fuel-cell technology were reviewed [13], and the cooling system used for PEMFCs has been described. These studies indicated that methods for maintaining the temperature in an optimal range must be developed to improve the output performance of a system.

To examine the effects of heat on energy storage devices, supercapacitor modules used in vehicles were subjected to thermal modeling and heat-management tests [14]; hotspots were located at the centers of the supercapacitors, and a forced-convection cooling system was required to enhance the life cycles. A previous study involved designing a watercooled cooling system for Ni-Cd batteries [15] in which a low-power pump propels the coolant and the coolant flow rate is regulated by a controllable valve. In addition, previous studies have evaluated the effects of air-cooled thermal-management systems on the output performance of lithium batteries $[16,17]$. The thermal dynamics behavior of batteries was examined and a model was constructed in $[18,19]$.

The aforementioned studies have indicated that a highperformance heat-dissipation system is required for green energy devices. To retain the configuration and volume of a heat-dissipation system (e.g., a battery-cooling system in the constraint trunk of an electric vehicle) and to raise heatdissipation capacity, nanofluids can be used because they transfer heat efficiently [20]. In [21], a thermal management system using an $\mathrm{Al}_{2} \mathrm{O}_{3} / \mathrm{W}$ coolant was experimentally studied. At various coolant flow rates and heating powers, the optimal weight fractions of nanoparticles as well as the optimal heat dissipation efficiency were derived. In addition to $\mathrm{Al}_{2} \mathrm{O}_{3}$, carbon nanotubes (CNTs) have attracted a considerable amount of attention because of their high aspect ratio, low specific gravity, large specific surface area, and high thermal conductivity. Thermal conductivity is crucial for improving heat-dissipation performance. The maximal thermal conductivity of a nanofluid containing multiwalled CNTs (MWCNTs) at a concentration of $0.6 \mathrm{vol} \%$ was enhanced by $38 \%$ [22]; similarly, the thermal conductivities of a CNT/ethylene glycol nanofluid of which the CNT concentration was $1.0 \mathrm{vol} . \%$ and a CNT/synthetic engine oil nanofluid of which the CNT concentration was 2.0 vol. \% were increased by $12.4 \%$ and $30 \%$, respectively, compared with a base fluid [23].

To examine the use of CNTs in heat dissipation, the heattransfer performance of CNT/water nanofluids (CNWNFs) was measured [24]. The measurements revealed that using CNTs at a concentration of $0.5 \mathrm{wt} . \%$ in a horizontal tube enhanced heat transfer by $350 \%$. Studies on the heat-transfer performance of an MWCNT/W nanofluid in a horizontal shell with a tube heat exchanger indicated that the nanofluid enhanced heat-dissipation effectively [25]. Moreover, the effects of the coolant temperature on the viscosity and convective coefficients of several nanofluids were compared, revealing that an increase in viscosity increased the amount of pumping power consumed [26, 27].

The aforementioned studies have examined the concept of hybrid green energy, the effects of temperature on output performance, and the properties and applications of nanofluids. However, few studies have investigated the use of MWCNT nanofluids in the heat-dissipation systems of hybrid green energy sources. This paper presents the properties of low-concentration CNWNFs, the selection of optimal MWCNT nanofluids, and the use of CNWNFs in a novel heat-dissipation system applied in simulated hybrid green-energy devices.

\section{Preparation and Basic Properties of Carbon Nanotube Nanofluids}

2.1. Preparation of Carbon Nanotube/Water Nanofluids. To prepare CNWNFs containing various MWCNT concentrations, the suitability of the nanotubes (outer diameter 20$30 \mathrm{~nm}$, Cheap Tubes Inc., USA) was first verified using scanning electron microscopy. Chitosan, which disperses MWCNTs and prevents them from clogging the pipes and tubes of systems, was added to deionized water at an optimal weight fraction $(\omega)$ of $0.2 \%$ [28]. The MWCNTs were added to the bulk liquid separately at weight fractions of $0.125 \%$, $0.25 \%$, and $0.5 \%$ and then dispersed by using a stirrer/hot plate (PC420D, Corning, USA), which operated at $600 \mathrm{rpm}$ for $1.5 \mathrm{~h}$; a homogenizer (YOM300D, Yotec, Taiwan), which operated at $6000 \mathrm{rpm}$ for $30 \mathrm{~min}$; and an ultrasonic liquid processor (Q700, Qsonica, USA), which operated for $30 \mathrm{~min}$ (on/off duty: 10/10 s), to ensure that the nanoparticles were stably suspended in the base liquid. Figure 1 shows the procedure used to produce CNWNFs.

\subsection{Fundamental Characteristics of Carbon Nanotube/Water} Nanofluids. Before evaluating the heat-dissipation capacity and measuring other performance indices, the basic properties of the CNWNFs were determined. A liquid density gravity meter (DA-130N, KEN, Japan) was used to measure the nanofluid density $\left(\rho_{\mathrm{nf}}\right)$. A $250 \mathrm{~g}$ sample consisting of water and the CNWNFs was placed in an isothermal unit (P-10, YSC, Taiwan), of which the temperature error was within $\pm 0.5^{\circ} \mathrm{C}$. The following equation expresses the relationship between $\rho_{\mathrm{nf}}$ and $\omega$ :

$$
\begin{aligned}
\rho_{\mathrm{nf}} & =(1-\phi) \rho_{\mathrm{bf}}+\phi \rho_{p} \\
& =\rho_{\mathrm{bf}}-\omega\left(\frac{\rho_{\mathrm{nf}}}{\rho_{p}}\right) \times\left(\rho_{\mathrm{bf}}-\rho_{p}\right) \\
& \longrightarrow \rho_{\mathrm{nf}}=\frac{\rho_{\mathrm{bf}}}{\left[1-\omega / \rho_{p} \times\left(\rho_{p}-\rho_{\mathrm{nf}}\right)\right]},
\end{aligned}
$$

where the volume fraction $\phi=\omega\left(\rho_{\mathrm{nf}} / \rho_{p}\right)$ and the subscripts $p$ and bf denote particle and bulk fluid (water), respectively. To measure the specific heat of the nanofluids $\left(c_{p, n f}\right)$, a differential scanning calorimeter (DSC, Q20, TA Instruments, USA) and mechanical cooling accessory (DSC and RCS40, TA Instruments) were used. A $15 \mathrm{mg}$ sample of the nanofluids was placed in an aluminum sample pan heated at a controlled temperature, which was increased at a rate of $4^{\circ} \mathrm{C} / \mathrm{min}$, and the specific heat was calculated by comparing with the known specific heat of sapphire. For theoretical analysis, 


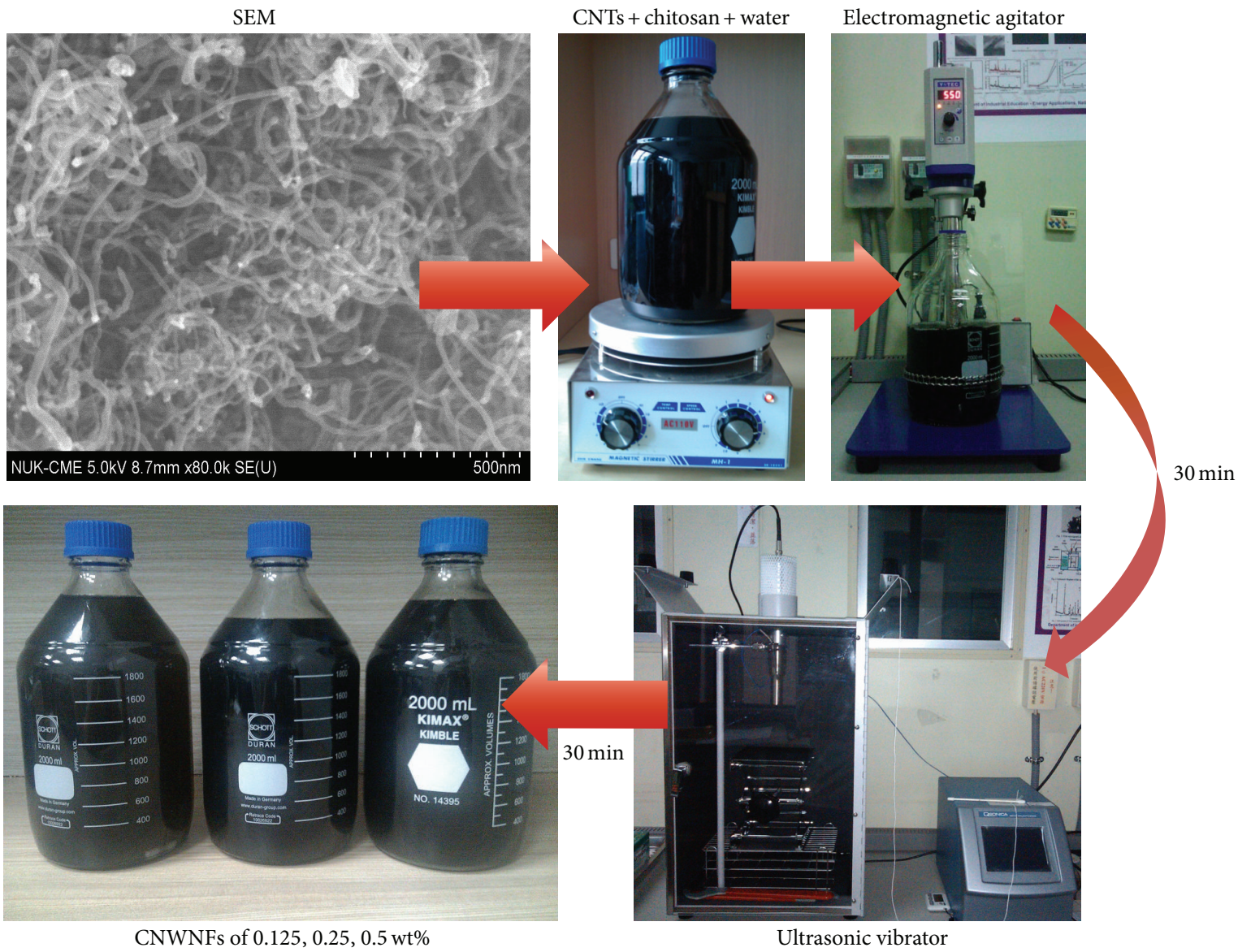

FIGURE 1: Procedures of CNWNFs with three weight fractions.

the following equation was used to express the inversely proportional relationship between $c_{p, \mathrm{nf}}$ and $\omega$ [29]:

$$
c_{p, \mathrm{nf}}=(1-\phi) c_{p, \mathrm{bf}}+\phi \cdot c_{p, p}=c_{p, \mathrm{bf}}-\omega \frac{\rho_{\mathrm{nf}}}{\rho_{p}}\left(c_{p, \mathrm{bf}}-c_{p, p}\right) .
$$

To measure the nanofluid viscosity $\left(\mu_{\mathrm{nf}}\right)$, which strongly influences the amount of pumping power consumed, a portable viscometer (VL700-T15, Hydramotion, England) was used. A $250 \mathrm{~g}$ sample was placed in the isothermal unit, and the average viscosity was calculated based on 5 measurements. For theoretical analysis, the viscosity equation presented in [30] was modified, and the relationship between $\mu_{\mathrm{nf}}$ and $\omega$ was expressed as follows:

$$
\mu_{\mathrm{nf}}=\left[1+2.5 \omega \frac{\rho_{\mathrm{nf}}}{\rho_{p}}+6\left(\omega \frac{\rho_{\mathrm{nf}}}{\rho_{p}}\right)^{2}\right] \mu_{\mathrm{bf}} .
$$

Equation (3) shows that $\mu_{\mathrm{nf}}$ increases when $\omega$ is increased. The fourth characteristic measured was thermal conductivity, which indicates the heat-transfer performance of the nanofluid. A thermal analyzer (KD2 Pro, Decagon Devices, USA) and the transient hotwire method were employed in determining the thermal conductivity. A $10 \mathrm{mg}$ sample was placed in a tube, and the tube was immersed in the isothermal unit. To reduce deviation among experiments, thermal conductivity was measured 5 times and the average was calculated.

In addition to the aforementioned characteristics, the heat convection from the air-cooled heat exchanger was used to determine the heat-dissipation capacity, which was proportional to the heat-transfer coefficient $\left(h_{\mathrm{nf}}\right)$, the contact area of the nanofluid $(A)$, and the temperature difference between the nanofluid $\left(T_{\mathrm{nf}}\right)$ and the atmosphere $\left(T_{\infty}\right)$ :

$$
\dot{Q}_{\mathrm{he}, \mathrm{nf}}=h_{\mathrm{nf}} A\left(T_{\mathrm{nf}}-T_{\infty}\right) \text {. }
$$

These fundamental characteristics of CNWNFs were used to explain the performance of the nanofluids in the heatdissipation system.

\section{Experimental Platform and Control Algorithm for Key Components}

3.1. Experimental Platform Construction. The experimental platform used in this study is illustrated in Figure 2. To control the operating temperatures of the dual energy source, the coolant was propelled by an electric pump to a 3-way proportional valve, which was used to control the flow rates of the 2 coolants, and the hybrid flow ratio (HFR) of the 


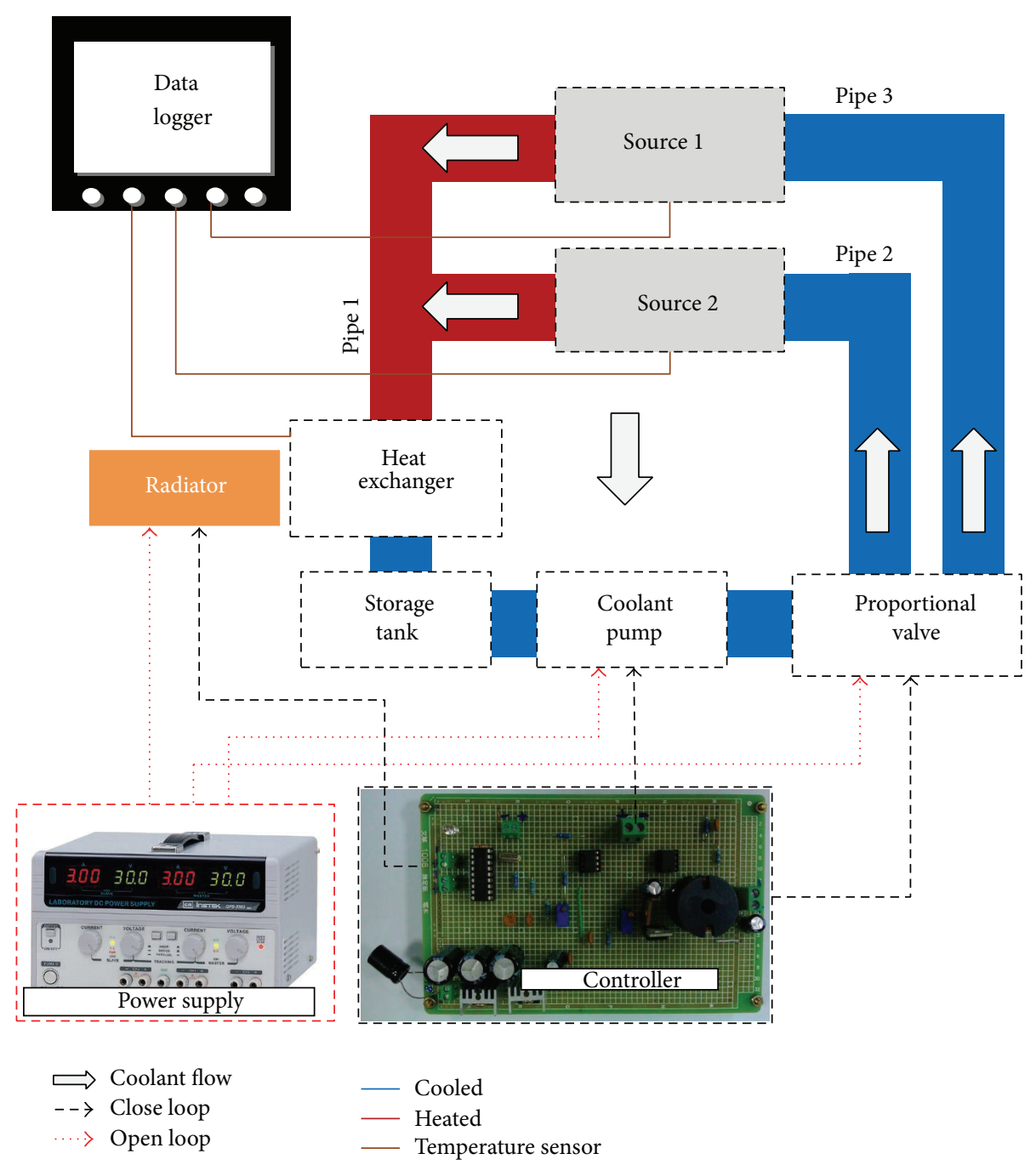

FIGURE 2: Schematics of the experimental hybrid energy system with CNWNFs.

dual energy source was determined based on the commanded voltage. The 2 coolant flows were separated into 2 pipes and constantly entered the heat sources (1 and 2). Both heat sources were composed of stainless steel containers (total volume: $500 \mathrm{~cm}^{3}$ ) equipped with an electrical heater, the heating power of which was regulated by a tunable autotransformer. The coolant in the 2 flow paths was heated to remove the simulated waste heat. The flows were then combined and delivered to an air-cooled finned-tube heat exchanger, which was integrated with a controlled fan system to provide forced convection [28]. The low-temperature coolant was then returned to a storage tank and the cycle was repeated. In evaluating the feasibility of using the CNWNFs in a heat-dissipation system, steady-state measurements and transient dynamics were key concerns. For steady-state measurements, an open-loop control configuration in which a power supply provided power to the fan system, coolant pump, and proportional valve at constant voltages was used. The transient dynamics were formulated using a closed-loop control configuration, and a microchip controller was used to manage the system. The 2 inputs were the feedback on/off signals from the temperature controllers of the heat sources, and the 3 outputs were the commanded voltages supplied to the fan system, coolant pump, and proportional valve.

3.2. Control Algorithm for Key Components. To maintain the optimal temperature of the dual energy source, appropriate rule-based control was employed in this study. Figure 3 shows a flowchart of the control strategies used for the key components. The 2 temperature controllers in Figure 2 first determined whether the actual temperature was higher or lower than the preset temperature and then delivered digital signals ( 1 for higher, 0 for lower) to the microchip controller. If any signal was 1, signifying that at least one actual temperature exceeded the ideal value, then the voltage of the proportional valve $\left(V_{\mathrm{PV}}\right)$ was varied to modify the HFR. The HFR was quantified as the mass flow rate of Heat Source 1 $\left(\dot{m}_{S 1}\right)$ divided by the total mass flow rate of the heat exchanger $\left(\dot{m}_{\mathrm{he}}\right)$ :

$$
\mathrm{HFR} \equiv \frac{\dot{m}_{\mathrm{S} 1}}{\dot{m}_{\mathrm{he}}}
$$




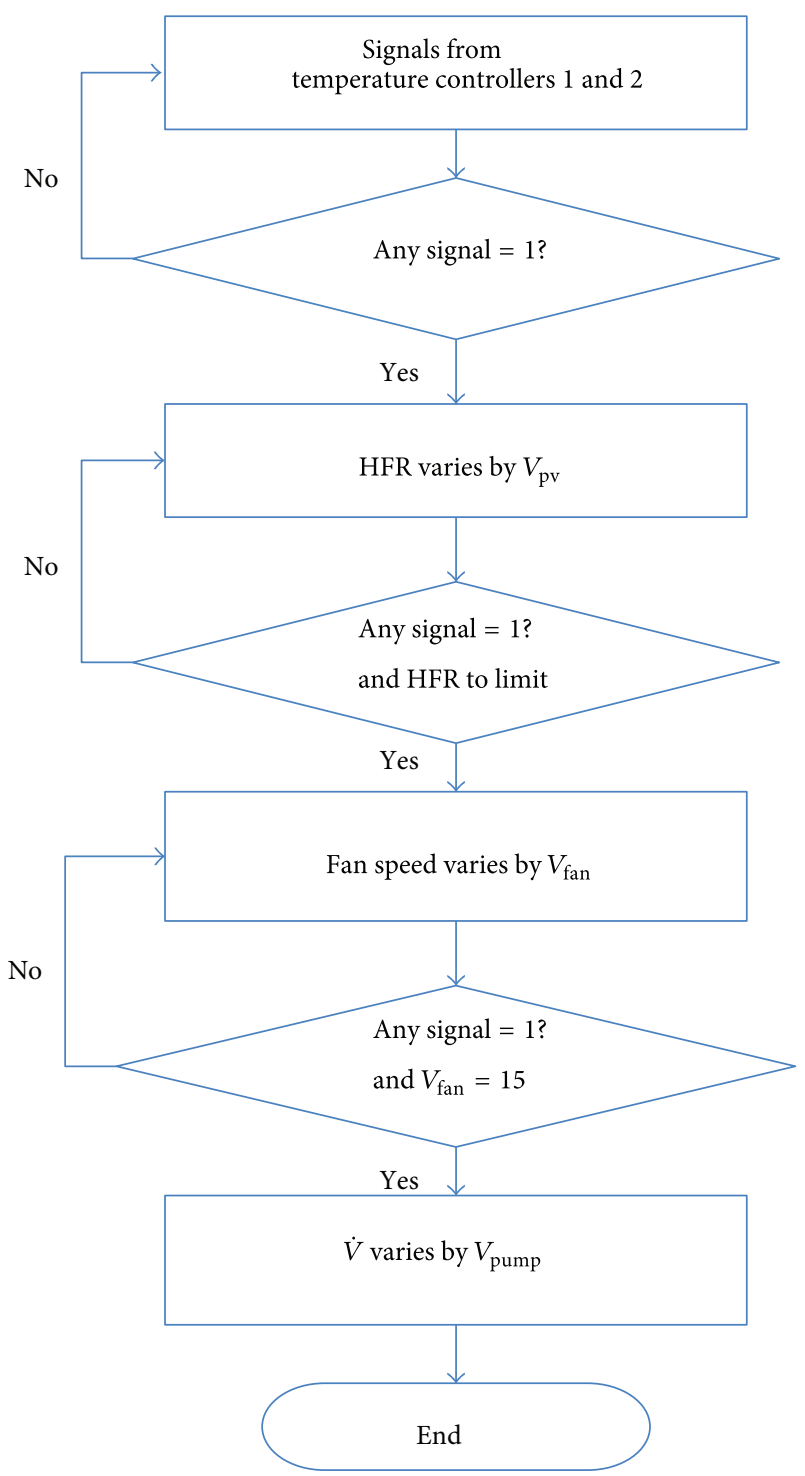

FIGURE 3: Flow chart of the control strategies for key components.

Therefore, the mass flow rate of Heat Source 2 was calculated as follows:

$$
\dot{m}_{S 2}=(1-\mathrm{HFR}) \dot{m}_{\mathrm{he}} .
$$

If the HFR was 1 (or 0) but the temperature of the heat source was still higher than the preset value, then the fan speed was regulated by the commanded voltage $V_{\text {fan }}$. If $V_{\text {fan }}$ was maximal $(15 \mathrm{~V})$ but at least one source remained overheated, then the coolant flow rate was increased by the tunable input voltage of the pump. If the 2 signals from the temperature controllers were 0 , then the inverse process of that shown in Figure 3 was executed to reduce the heat-dissipation capacity and save energy.

3.3. Selection of Optimal Weight Fraction. To determine the optimal weight fractions of the MWCNTs, steady-state experiments were conducted. The heat-dissipation power of
TABLE 1: Experimental data of CNWNFs properties.

\begin{tabular}{lccccc}
\hline \multicolumn{5}{c}{ Experimental data } & \\
Item & $T$ & Water & 0.125 wt.\% & 0.25 wt.\% & 0.5 wt.\% \\
\hline Density & 40 & 991.7 & 992.5 & 994.4 & 996.6 \\
$\left(\rho_{\text {nf }}\right)$ & 50 & 986.0 & 987.8 & 988.9 & 993.0 \\
& 60 & 981.0 & 981.8 & 983.1 & 986.6 \\
\hline \multirow{2}{*}{ Specific heat } & 40 & 4.18 & 4.59 & 4.53 & 4.15 \\
$\left(c_{p, \text { nf }}\right)$ & 50 & 4.18 & 4.60 & 4.55 & 4.16 \\
& 60 & 4.18 & 4.62 & 4.57 & 4.16 \\
\hline \multirow{2}{*}{ Viscosity } & 40 & 0.65 & 0.7 & 0.82 & 1.44 \\
$\left(\mu_{\text {nf }}\right)$ & 50 & 0.55 & 0.68 & 0.7 & 1.12 \\
& 60 & 0.52 & 0.56 & 0.6 & 0.9 \\
\hline Thermal & 40 & 0.62 & 0.50 & 0.58 & 0.62 \\
conductivity & 50 & 0.64 & 0.74 & 0.94 & 1.49 \\
$\left(k_{\text {nf }}\right)$ & 60 & 0.65 & 0.97 & 1.25 & 2.20 \\
\hline
\end{tabular}

the heat exchanger $\left(\dot{Q}_{\mathrm{he}}\right)$, which was measured with water and the 3 CNWNFs, was defined using the following equation:

$$
\dot{Q}_{\mathrm{he}}=\dot{m}_{\mathrm{he}} c_{p, i}\left(T_{i, \mathrm{he}}-T_{o, \mathrm{he}}\right) .
$$

The parameter $\dot{m}_{\text {he }}$ was calculated as $\rho_{\mathrm{nf}} \times \dot{V}_{\mathrm{he}} ; \rho_{\mathrm{nf}}$ is listed in Table 1, and the volume flow rate of heat exchanger $\left(\dot{V}_{\text {he }}\right)$ was measured using a flow meter. The inlet and outlet temperatures $\left(T_{i, \text { he }}\right.$ and $\left.T_{o, \text { he }}\right)$ were measured using 2 T-type thermocouples.

To quantify the enhancement of heat dissipation under all tested conditions, an index called the heat dissipation enhancement ratio (HDER) was used. The HDER was defined as the heat dissipation of the CNWNFs divided by the heat dissipation of water:

$$
\text { HDER } \equiv \frac{\dot{Q}_{\mathrm{henf}}}{\dot{\mathrm{Q}}_{\mathrm{he}, w}},
$$

where $w$ denotes water. Based on (7) and (8), a performance index for selecting the optimal weight fraction of the CNTs, the specific heat dissipation enhancement ratio (SHDER), was defined. The SHDER was calculated by dividing the HDER by the combined electrical power consumed by the fan, controller, proportional valve, and coolant pump. In physical terms, the SHDER reflects the nanofluid-to-water enhancement of heat-dissipation capacity divided by the electrical power consumed $\left(\dot{Q}_{\text {elec }}\right)$. A large SHDER value indicates that the system efficiently dissipates heat:

$$
\begin{aligned}
\text { SHDER } & \equiv \frac{\dot{Q}_{\text {he,nf }} / \dot{Q}_{\text {elec,nf }}}{\dot{Q}_{\text {he, } w} / \dot{Q}_{\text {elec }, w}}=\frac{\text { HDER }}{\left(\dot{Q}_{\text {elec }, n f} / \dot{Q}_{\text {elec }, w}\right)} \\
& =\frac{\operatorname{HDER} \times \dot{Q}_{\text {elec }, w}}{\dot{Q}_{\text {elec,nf }}} .
\end{aligned}
$$

3.4. Stability Analysis. To maintain highly efficient system operation (i.e., operation at the optimal temperature), 
temperature stability is crucial. The relative standard deviation of temperature variation, $\mathrm{RSD}_{T_{S i, i=1,2}}$, is expressed as follows:

$$
\begin{aligned}
\operatorname{RSD}_{T_{S i, i=1,2}} & =\frac{\sqrt{(1 / N) \sum_{t=1}^{N}\left(T_{S i}-\bar{T}_{S i}\right)^{2}}}{\bar{T}_{S i}} \times 100 \%, \\
\bar{T}_{S i} & \equiv \frac{1}{N}\left(T_{S i}(1)+T_{S i}(2)+\cdots+T_{S i}(N)\right),
\end{aligned}
$$

where $N$ is the number of times that the temperature is sampled and $\bar{T}$ is the average temperature during the elapsed time. In physical terms, $\mathrm{RSD}_{T_{S, i=1,2}}$ indicates the extent of temperature variation compared with the average temperature as a function of the elapsed time after the actual temperature reaches the target temperature for the first time. A lower RSD represents greater stability of the control from the heat dissipation system.

\section{Experimental Results and Discussion}

4.1. Fundamental Characteristics of the Carbon Nanotube/Water Nanofluids. Table 1 shows the experimental results regarding the fundamental characteristics of the CNWNFs. The density and thermal conductivity of MWCNTs are higher than those of water, but the specific heat of MWCNTs is lower than that of water. The density and specific heat of chitosan are higher than those of water, but the thermal conductivity of chitosan is lower than that of water. Therefore, varying the combinations of MWCNTs, chitosan, and water influences the properties of CNWNFs. When the CNT concentration (weight fraction) was increased, the density and thermal conductivity of the CNWNF increased; however, the specific heat decreased. Increasing the weight fraction of chitosan caused the specific heat of the CNWNF to increase and the density of the CNWNF to increase slightly. Thus, the fundamental characteristics of CNWNFs can be determined based on the proportions of MWCNTs and chitosan. According to (1), the density of the CNWNFs increased because of the high density of the CNTs (i.e., when $\omega$ was high, $\rho_{\mathrm{nf}}$ was high). However, when the temperature was increased, the molecules in the nanofluids became energized and, therefore, the fluid volume increased, leading to a linear reduction in $\rho_{\mathrm{nf}}$. The specific heat of the nanofluids is determined according to the combined effects of the nanoparticles and the dispersant, chitosan. Values of $c_{p, \mathrm{nf}}$ at $0.125 \mathrm{wt} . \%$ and $0.25 \mathrm{wt} . \%$ were higher than that of water. Only $c_{p \text {,nf }}$ at 0.5 wt.\% was slightly lower than the specific heat of water. Moreover, when the temperature was raised, $c_{p, \mathrm{nf}}$ increased. Equation (3) indicates that $\mu_{\mathrm{nf}}$ rises when $\omega$ is increased. However, when the temperature was raised, the nanoparticles began to move more vigorously; therefore, $\mu_{\mathrm{nf}}$ decreased. Lastly, the thermal conductivity of the CNWNF $\left(k_{\mathrm{nf}}\right)$ was concomitantly increased and reduced by the MWCNTs and the chitosan dispersant surrounding the CNTs, respectively. At $40^{\circ} \mathrm{C}$, the $k_{\mathrm{nf}}$ value of the $0.125 \mathrm{wt} . \%$ mixture was lower than the thermal conductivity of water; moreover, when the CNT weight fraction was increased, $k_{\mathrm{nf}}$
TABLE 2: Heat dissipation at 3 heating ratios $(2: 8,4: 6$, and $5: 5), 2$ flow rates $(3$ and $5 \mathrm{~L} / \mathrm{min})$, and 3 CNTs weight fractions $(0.125,0.25$, and $0.5 \mathrm{wts} \%)$.

\begin{tabular}{lcccccc}
\hline & \multicolumn{3}{c}{ HRs@3 L/min } & \multicolumn{3}{c}{ HRs@5 L/min } \\
& $2: 8$ & $4: 6$ & $5: 5$ & $2: 8$ & $4: 6$ & $5: 5$ \\
\hline Water & 920.0 & 911.7 & 907.5 & 986.3 & 982.8 & 972.3 \\
0.125 wt\% & 960.0 & 976.1 & 994.5 & 1068.0 & 1083.3 & 1064.2 \\
0.25 wt\% & 879.6 & 924.9 & 890.9 & 1035.3 & 974.8 & 978.6 \\
0.5 wt\% & 798.5 & 717.4 & 748.5 & 973.8 & 970.3 & 966.9 \\
\hline
\end{tabular}

increased because, at high temperatures $\left(50^{\circ} \mathrm{C}\right.$ and $\left.60^{\circ} \mathrm{C}\right)$, the heat energized and enhanced the movement of MWCNTs, spreading the heat efficiently in the CNWNFs.

4.2. Steady-State Performance and the Optimal Weight Fraction. To determine the optimal CNT weight fraction, the steady-state performance was evaluated. Three CNT weight fractions were tested, and the low and high coolant flow rates were set at 3 and $5 \mathrm{~L} / \mathrm{min}$, respectively. The heating ratios for the dual energy source were set at $2: 8,4: 6$, and $5: 5$, and the hybrid total power was $1000 \mathrm{~W}$. Table 2 summarizes the heat-dissipation capacity of the heat exchanger, which was calculated according to (7), when water and the 3 CNWNF samples were used.

The results indicated that heat was dissipated more efficiently at the high coolant flow rate $(5 \mathrm{~L} / \mathrm{min})$ than at the low flow rate $(3 \mathrm{~L} / \mathrm{min})$, as expected based on engineering principles. The heat-dissipation capacity was the highest, second highest, and lowest at CNT concentrations of $0.125 \mathrm{wt} . \%$, 0.25 wt. $\%$, and 0.5 wt. $\%$, respectively. This is because when a viscous coolant (e.g., 0.5 wt.\%) flows through the finned tube in the heat exchanger, the coolant cannot spread outward from the center of the tube, resulting in a reduction in the contact area between the coolant and the tube wall. According to the reduction in $A$ in (4), $\dot{Q}_{\text {he }}$ also decreased and the parameter $\dot{Q}_{\text {he }}>1000$ because the coolant removed the heat generated by the key components of the system.

The HDERs were calculated based on values in Table 2 and (8), and the results (Figure 4) revealed that only the HDERs of the nanofluids with an MWCNT concentration of $0.125 \mathrm{wt} . \%$ were greater than 1.0 at the 3 heat ratios tested, indicating that the heat-dissipation capacities of these nanofluids were greater than that of pure water. When the weight fraction of the MWCNTs was increased, the HDERs decreased because of the previously described effect of viscosity. Moreover, on average, the HDERs were higher at a flow rate of $5 \mathrm{~L} / \mathrm{min}$ than at a flow rate of $3 \mathrm{~L} / \mathrm{min}$. At the high coolant flow rate (which requires a high pumping power), a greater amount of coolant might be squeezed from the center of the finned tubes to the sides compared with the low flow rate, thereby increasing the contact area between the coolant and the tube wall and enhancing the heat-dissipation capacity as described previously.

A crucial factor used to evaluate the system performance in this study was the electrical power consumed. Figure 5 shows the pumping power at 3 and $5 \mathrm{~L} / \mathrm{min}$ with respect to various HFRs when water and the nanofluids 


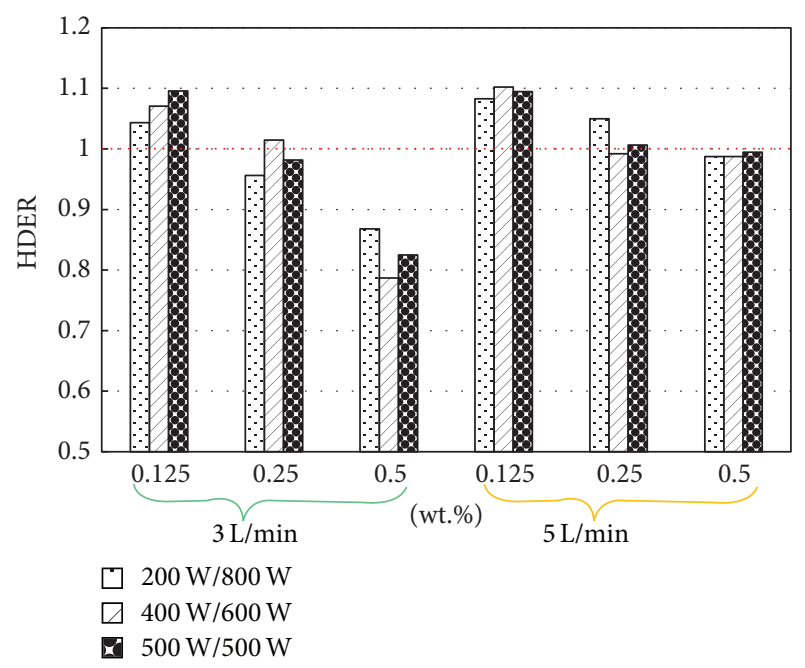

FIgURE 4: Heat dissipation enhanced ratios (HDERs) under 3 heating ratios (ERs) and 3 CNTs weight fractions at $\dot{V}=3 \mathrm{~L} / \mathrm{min}$ and $\dot{V}=5 \mathrm{~L} / \mathrm{min}$.

with 3 MWCNT weight fractions $(0.125,0.25$, and 0.5 wt.\%) were used. Because the fluids cannot be compressed and because they are homogeneously dense and viscous, the HFRs influence the pumping power slightly. As expected, when the MWCNT weight fractions were increased, the viscosity increased (Table 1), and, therefore, the pumping power had to be increased to maintain the coolant flow rate. Thus, the pumping power at the high coolant flow rate was higher than that at the low flow rate.

Figure 6 shows the values of the SHDERs determined experimentally at 3 heating ratios and flow rates of 3 and $5 \mathrm{~L} / \mathrm{min}$ when the CNWNFs with $3 \mathrm{MWCNT}$ weight fractions were used. The SHDER values of the nanofluids with a CNT concentration of $0.125 \mathrm{wt} . \%$ were greater than those of water, indicating that the system was more efficient when CNWNFs were applied. By contrast, at 0.25 and $0.5 \mathrm{wt} . \%$, the SHDERs were lower than 1.0, indicating that the system efficiency was lower than that achieved by using water; the SHDER value at a CNT concentration of $0.5 \mathrm{wt} . \%$ and heating powers of 400 and $600 \mathrm{~W}$ decreased to 0.62 . The SHDERs at the high flow rate $(5 \mathrm{~L} / \mathrm{min})$, on average, were higher than those at the low flow rate $(3 \mathrm{~L} / \mathrm{min})$. Although the pump consumed more electrical power at the high coolant flow rate (Figure 5), the HDER was greater than the increase in the electrical power consumed. Thus, the overall system efficiency was greater at the high coolant flow rate than at the low flow rate.

Table 3 shows the results regarding the steady-state temperatures of the 2 heat sources and $\Delta T\left(\Delta T \equiv T_{S 2}-T_{S 1}\right)$ at 3 heating ratios, 4 selected HFRs, and $\dot{V}=3 \mathrm{~L} / \mathrm{min}$. The CNWNFs were used as the coolant. At a heating ratio of $2: 8$, according to (5), the coolant mass flow rate of Heat Source 2 was greater than that of Heat Source 1 at HFR = 0.06 . Because of the low heating power of Heat Source 1 at a low coolant mass flow rate, the disparity in steady-state temperatures between the 2 energy sources was small (only $-3.9^{\circ} \mathrm{C}$ ). However, when the HFR was higher, more of the

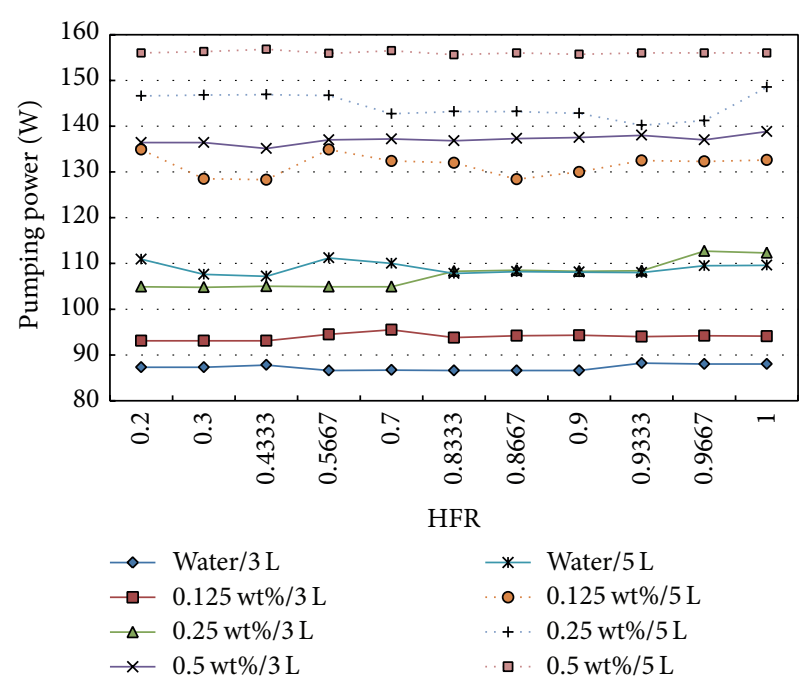

Figure 5: Pumping power for water and 3 CNTs weight fractions $(0.125,0.25$, and 0.5 wts $\%)$ at 3 and $5 \mathrm{~L} / \mathrm{min}$ with respect to HFRs.

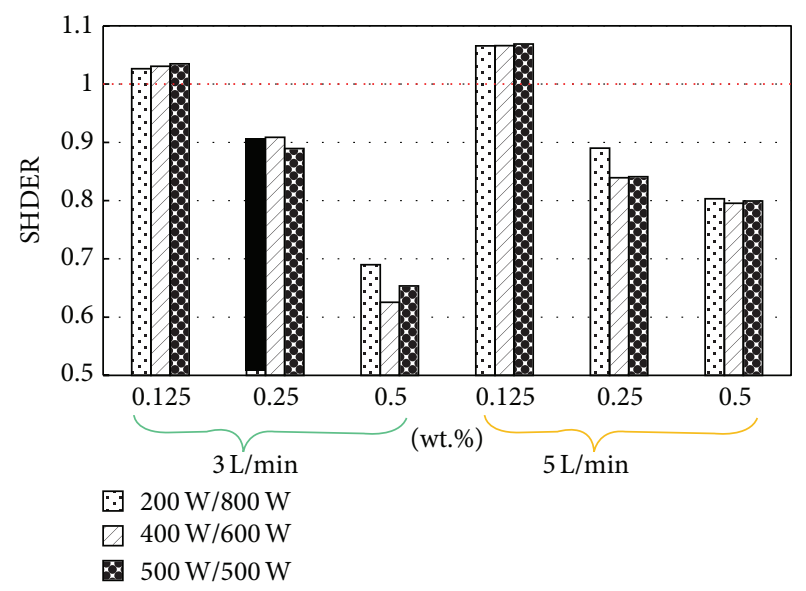

FIGURE 6: Specific heat dissipation enhanced ratios (SHDERs) under three heating ratios (ERs) and 3 CNTs weight fractions at $\dot{V}=$ $3 \mathrm{~L} / \mathrm{min}$ and $\dot{V}=5 \mathrm{~L} / \mathrm{min}$.

CNWNF entered Heat Source 1 and removed more waste heat, and, concurrently, the nanofluid entered Heat Source 2 and removed less heat. The $\Delta T$ reached a maximum of $42.3^{\circ} \mathrm{C}$ at $\mathrm{HFR}=0.93$. At a heating ratio of $4: 6$, the amounts of waste heat of the 2 sources were similar and, therefore, the $\Delta T$ ranged from $-8.6^{\circ} \mathrm{C}$ at $\mathrm{HFR}=0.06$ to $30.1^{\circ} \mathrm{C}$ at $\mathrm{HFR}=0.93$. Furthermore, at a heating ratio of $5: 5$, because the heat generated by the 2 sources was equal, the absolute values of the $\Delta T$ at HFR $=0.06\left(\dot{m}_{S 1}: \dot{m}_{S 2}=6: 94\right)$ and HFR $=0.93\left(\dot{m}_{S 1}: \dot{m}_{S 2}=93: 7\right)$ were similar $\left(19\right.$ and $17.5^{\circ} \mathrm{C}$, resp.). The experimental results obtained at the high coolant flow rate $(5 \mathrm{~L} / \mathrm{min})$ are presented in Table 4 , which shows 2 key differences from the results shown in Table 3 . First, at a specified HSR and heating ratio, $T_{S 1}$ and $T_{S 2}$ were lower at the high flow rate than at the low flow rate because of the increase in the heat-dissipation capacity described in (7) $\left(\dot{m}_{\text {he }}\right.$ increases when $\dot{V}_{\text {he }}$ is increased). Second, the $\Delta T$ was lower 
TABLE 3: $T_{S 1}, T_{S 2}$, and $\Delta T$ under three heat ratios and four HFRs at $\dot{V}=3 \mathrm{~L} / \mathrm{min}$.

\begin{tabular}{|c|c|c|c|c|c|c|c|c|c|}
\hline \multicolumn{10}{|c|}{ Heating ratio } \\
\hline \multirow{2}{*}{ HFR } & \multicolumn{3}{|c|}{$2: 8$} & \multicolumn{3}{|c|}{$4: 6$} & \multicolumn{3}{|c|}{$5: 5$} \\
\hline & $T_{S 2}$ & $T_{S 1}$ & $\Delta T$ & $T_{S 2}$ & $T_{S 1}$ & $\Delta T$ & $T_{S 2}$ & $T_{S 1}$ & $\Delta T$ \\
\hline 0.06 & 41.7 & 45.6 & -3.9 & 39.6 & 48.2 & -8.6 & 40.6 & 59.6 & -19 \\
\hline 0.26 & 43.4 & 41.2 & 2.2 & 40.3 & 42.8 & -2.5 & 41.8 & 46.6 & -4.8 \\
\hline 0.66 & 49.1 & 39.5 & 9.6 & 44.3 & 38.9 & 5.4 & 42.8 & 40 & 2.8 \\
\hline 0.93 & 81.2 & 38.9 & 42.3 & 68.5 & 38.4 & 30.1 & 57.3 & 39.8 & 17.5 \\
\hline
\end{tabular}

TABLE 4: $T_{S 1}, T_{S 2}$, and $\Delta T$ under three heat ratios and four HFRs at $\dot{V}=5 \mathrm{~L} / \mathrm{min}$.

\begin{tabular}{|c|c|c|c|c|c|c|c|c|c|}
\hline \multicolumn{10}{|c|}{ Heat ratio } \\
\hline \multirow{2}{*}{ HFR } & \multicolumn{3}{|c|}{$2: 8$} & \multicolumn{3}{|c|}{$4: 6$} & \multicolumn{3}{|c|}{$5: 5$} \\
\hline & $T_{S 1}$ & $T_{S 2}$ & $\Delta T$ & $T_{S 1}$ & $T_{S 2}$ & $\Delta T$ & $T_{S 1}$ & $T_{S 2}$ & $\Delta T$ \\
\hline 0.06 & 41.2 & 44 & -2.8 & 38.5 & 45 & -6.5 & 39.8 & 50.7 & -10.9 \\
\hline 0.28 & 41.3 & 40 & 1.3 & 39.2 & 40.5 & -1.3 & 39.6 & 42.2 & -2.6 \\
\hline 0.68 & 44.9 & 39.1 & 5.8 & 42.4 & 39 & 3.4 & 41.4 & 39.4 & 2 \\
\hline 0.92 & 60.2 & 38.6 & 21.6 & 55.2 & 38 & 17.2 & 49.9 & 38.8 & 11.1 \\
\hline
\end{tabular}

at a specified HFR and heating ratio when the high flow rate was applied than when the low flow rate was applied. Because more heat was removed with higher than lower $\dot{m}_{\text {he }}\left(\right.$ or $\left.\dot{V}_{\text {he }}\right)$, the difference in waste heat between Heat Sources 1 and 2 was smaller at the high flow rate (i.e., greater heat dissipation and smaller $\Delta T$ ). These results suggested that, when the disparity in the target temperatures of the 2 energy sources is large, a low coolant flow rate should be used, enabling the system to consume less electrical power. Conversely, when the target temperatures of the energy sources differ only slightly, a high coolant flow rate should be used, thus enhancing the heatdissipation capacity of the system.

4.3. Transient Dynamics and Stability Analysis. To assess experimentally the feasibility of applying the CNWNFs as coolants in the hybrid dissipation system, the closed-loop control configuration described in Section 2 was adopted. Heat Sources 1 and 2 were assumed to be a lithium battery module and a PEMFC module of which the optimal (goal, subscript $g$ ) temperatures were $40^{\circ} \mathrm{C}$ and $60^{\circ} \mathrm{C}\left(T_{b, g}\right.$ and $\left.T_{f c, g}\right)$, respectively.

Figure 7 (a) shows the temperature variation of the energy sources and the control of the HFRs when the CNWNFs and water were used at a heating ratio of $2: 8$. After the $63 \mathrm{rd} \mathrm{sec}-$ ond, the 2 simulated sources were heated. To evenly distribute the coolant to the 2 sources, the HFR was initially increased to 0.35 . Because water has a lower thermal conductivity (more heat accumulated in water than in the CNWNFs) and heat capacity (the temperature of water varied more than that of the nanofluids did at the same generated heat) (Table 1) than the nanofluids do, the values of $T_{S 1, a, w}$ and $T_{S 2, a, w}$ rose faster when water was used than when the CNWNFs (and $\left.T_{S 2, a, \mathrm{nf}}\right)$ were used before the 415 th second. When $T_{S 1, a, w}$ reached $40^{\circ} \mathrm{C}$, the temperature controller sent a triggered signal to the microchip controller shown in Figure 3, and the input voltage of the proportional valve was changed to raise the HFR according to (5). Consequently, more coolant flowed to the simulated battery and, therefore, $T_{S 1, a, w}$ began to decrease and then fluctuated within $40 \pm 2^{\circ} \mathrm{C}$. Concurrently, $T_{S 2, a, w}$ increased sharply because of the sudden drop in $\dot{m}_{S 1, w}$ and because of the high heating power $(800 \mathrm{~W})$. Similarly, when $T_{S 2, a, w}$ exceeded $60^{\circ} \mathrm{C}$ with an "overshoot" and HFR equaled 1.0, the fan system was activated to remove excess heat through forced convection. The parameter $T_{S 2, a, w}$ then gradually decreased and fluctuated within $60 \pm 2^{\circ} \mathrm{C}$. When the CNWNFs were used, because the thermal conductivity and heat capacity were higher than those of water, $T_{S 1, a, n f}$ rose at a lower rate than it did when water was used. Consequently, the HFR rose at the 466th second, later than the time at which it increased when water was used. The temperature varied within a smaller range $\left( \pm 1^{\circ} \mathrm{C}\right)$ than it did when water was used, indicating that the inherent advantage of the CNWNFs is stability. These characteristics were confirmed based on the smaller slope of the rise in $T_{S 2, a, n f}$ and the temperature variation of the temperature within a smaller range $\left( \pm 0.5^{\circ} \mathrm{C}\right)$ observed when the CNWNFs were used. Figure 7 (b) shows the control of the fan system. Before the 431st second, the fan did not operate because the heatdissipation capacity was sufficient. After $V_{\mathrm{PV}}=3.0$, when $T_{S 1}$ or $T_{S 2}$ exceeded the preset temperature, the fan was activated at an initial voltage of $10 \mathrm{~V}$ and then rose continually with a constrained slope; the voltage then decreased when less heat dissipation was required. Because the $T_{S 1}$ value of water reached $40^{\circ} \mathrm{C}$ before that of the CNWNFs did, the HFR of water reached 1.0 before that of the CNWNFs did, causing the fan to be activated sooner (Second 431). The fan was deactivated at the 725 th second because both $T_{S 1}$ and $T_{S 2}$ were below the target temperatures but then was activated again at the 806 th second because $T_{S 1}$ reached $40^{\circ} \mathrm{C}$. When the CNWNFs were used, the temperatures of the energy sources were controlled tightly and were more stable than the temperatures measured when water was used because of the higher heat capacity and thermal conductivity of the 

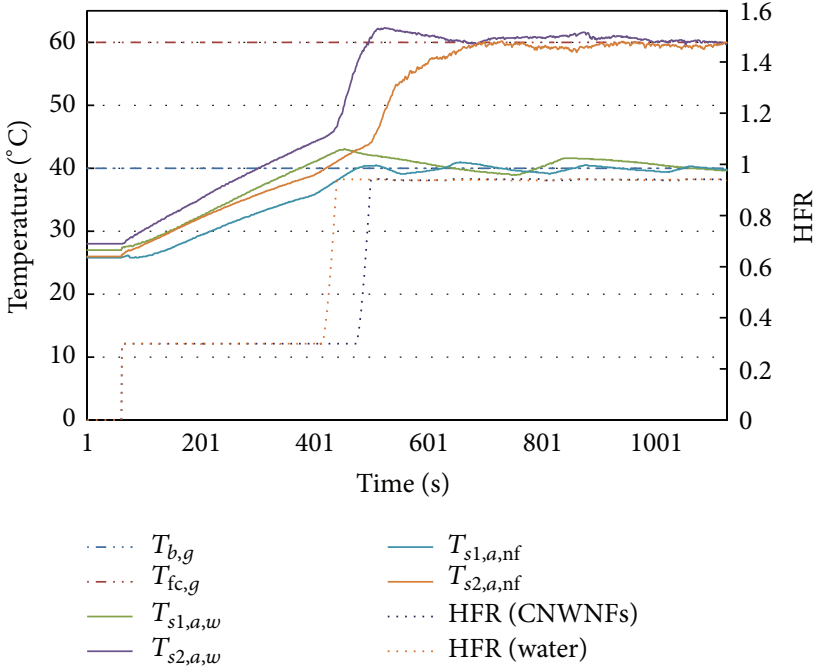

(a)

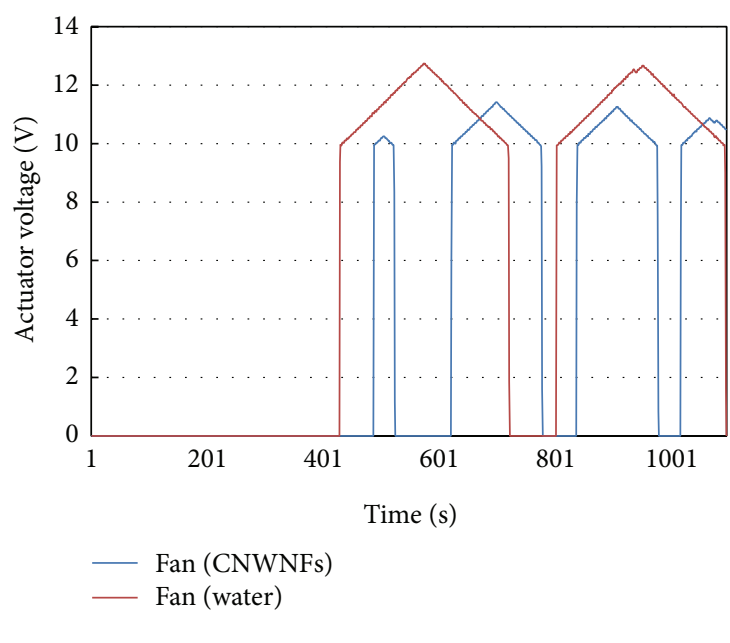

(b)

FIGURE 7: (a) Temperature variation of dual energy sources and control of HFRs; (b) controlled voltage of fan system in CNWNFs and water cases at the heating ratio of $2: 8$.

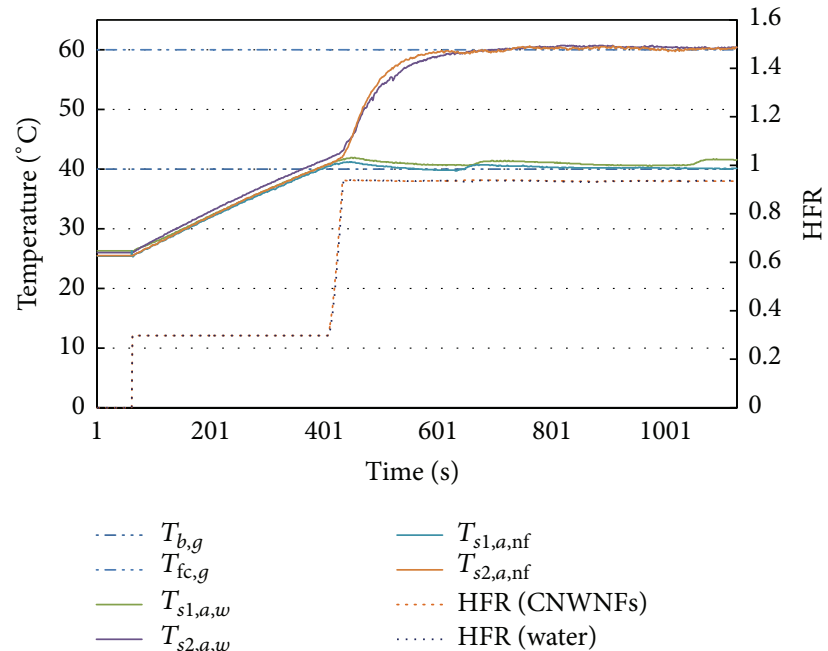

(a)

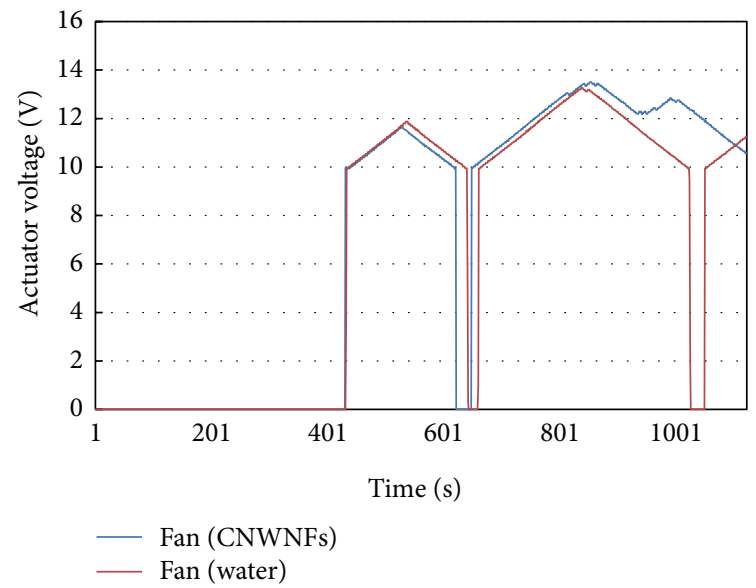

(b)

FIGURE 8: (a) Temperature variation of dual energy sources and control of HFRs; (b) controlled voltage of fan system in CNWNFs and water cases at the heating ratio of $4: 6$.

nanofluids; therefore, the activation period was shorter (less electrical power consumption) and the control voltage was lower than those observed when water was used.

Figure 8 shows a plot of the temperature variation when a heating ratio of $4: 6$ was applied. For both water and the CNWNFs, the $T_{S 1, a}$ and $T_{S 2, a}$ profiles were nearly identical before the 400th second. This is because the CNWNFs have a higher specific heat than water does (Table 1), preventing the temperature from rising and because water has a higher thermal conductivity than the CNWNFs do ( 0.62 versus 0.50 ; Table 1) near or below $40^{\circ} \mathrm{C}$; thus, the heat spreads to the coolant more efficiently, enabling more heat energy to be released from the pipes into the atmosphere through natural convection. These 2 factors prevented the temperature from rising and, because of their influence, the temperature profiles of the CNWNFs and water match closely.

When $T_{S 2}$ reached $60^{\circ} \mathrm{C}$, although the CNWNFs exhibited a lower thermal conductivity than water did (Table 1), because of the combined effects of heat convection and heat capacity, the 2 temperature profiles remained similar. Therefore, the HFRs for water and the CNWNFs varied almost identically. Regarding the operation of the fan system depicted in Figure 8(b), based on the control logic presented in Figure 3, the activation and deactivation times for water 


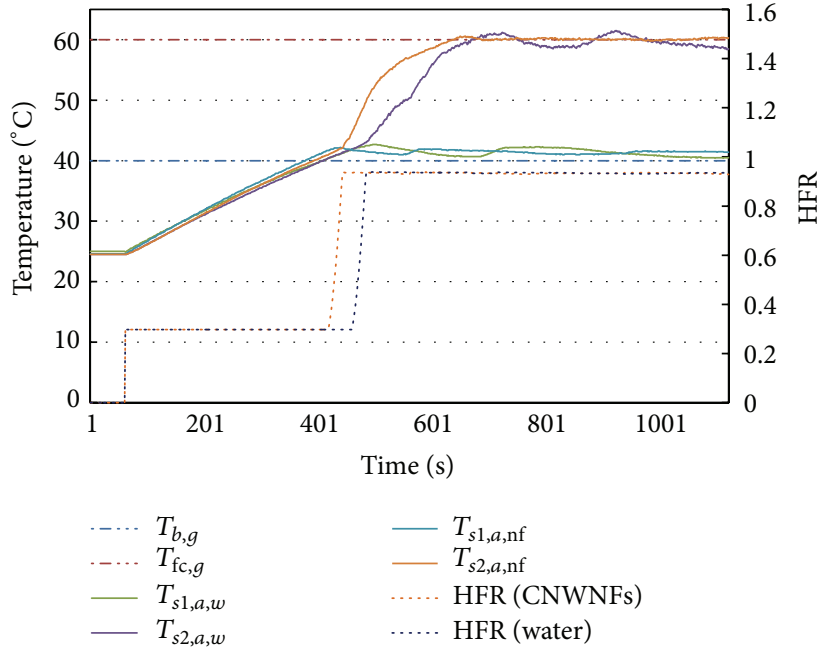

(a)

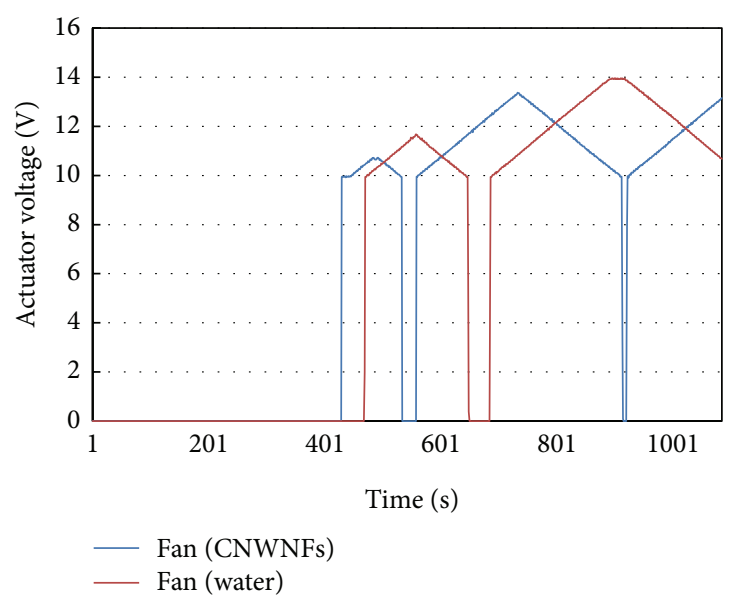

(b)

FIGURE 9: (a) Temperature variation of dual energy sources and control of HFRs; (b) controlled voltage of fan system in CNWNFs and water cases at the heating ratio of $5: 5$.

and the CNWNFs were nearly identical because their temperature profiles are similar.

Figure 9 shows the temperature variation when a heating ratio of 5:5 was applied. Like the temperature profiles obtained at a heating ratio of $4: 6$, the 4 temperature profiles matched well before the 420th second. When $T_{S 2}$ exceeded $40^{\circ} \mathrm{C}$, the higher thermal conductivity of the CNWNFs at a high heating power $(800 \mathrm{~W})$ caused the temperature increase to be greater than that of water, and the higher heat capacity and heat convection of CNWNFs caused the temperature decrease to be greater than that of water. At a low heating power $(200 \mathrm{~W})$, the $T_{S 1}$ temperature profiles for water and the CNWNFs were similar because of the tradeoffs among thermal conductivity, heat convection, and heat capacity. The fan system shown in Figure 9(b) was activated earlier when the CNWNFs were used than when water was used because of the time at which the HFR reached 1.0. However, when the CNWNFs were used, because of the steady-state error of $T_{S 1, a, \mathrm{nf}}$, the fan system operated for most of the time. In addition, large variations in $T_{S 1, a, w}$ and $T_{S 2, a, w}$ triggered the fan system several times. These results indicated that the stability of the coolant critically affects the energy consumed by a heat-dissipation system.

The RSDs and the enhancements of $T_{S 1}$ and $T_{S 2}$ at the 3 heating ratios when water and the CNWNFs were used, which were calculated based on the results shown in Figures 7-9, are presented in Table 5. For $T_{S 1, a, w}$, the average RSD for the 3 heating ratios was 2.166, whereas the average RSD for $T_{S 1, a, n f}$ was 1.337 . Thus, the stability increased by $36.37 \%$. For $T_{S 2, a, w}$, the average RSD for the 3 heating ratios was 1.150 , whereas the average RSD for $T_{S 2, a, n f}$ was 0.713 . Thus, stability increased by $36.07 \%$. When the nanofluids were used for both $T_{S 1}$ and $T_{S 2}$, the stability was increased by an average of $36.22 \%$, indicating that the CNWNFs rather than water can be used to maintain the actual temperature near the target temperature and thereby improve the performance of the heat-dissipation system.
The experimental results of this study revealed that the heat-dissipation capability, transient dynamics, and temperature stability of low-weight-fraction $(0.125 \%)$ CNWNFs are more favorable than those of pure water for application in thermal management systems used for green energy sources. Hence, according to a benefit analysis of an MWCNT hybrid (PEMFC and lithium battery) cooling system in which a CNWNF with an MWCNT concentration of $0.125 \mathrm{wt} . \%$ is applied, we recommend that (1) the operation temperatures for lithium batteries and fuel cells be fixed within the optimal efficiency zone $\left(40^{\circ} \mathrm{C}\right.$ and $\left.60^{\circ} \mathrm{C}\right)$ and (2) the same probability be applied for 3 HFRs $(200 \mathrm{~W}: 800 \mathrm{~W}$, $400 \mathrm{~W}: 600 \mathrm{~W}$, and $500 \mathrm{~W}: 500 \mathrm{~W}$ ) of dual energy sources. Figure 6 shows that the CNWNF with an MWCNT concentration of $0.125 \mathrm{wt} \%$ exhibited improvements in heat exchange efficiency (SHDER) of approximately $3 \%$ at a coolant flow rate of $3 \mathrm{~L} / \mathrm{min}$ and $7 \%$ at a flow rate of $5 \mathrm{~L} / \mathrm{min}$ compared with water. This result indicated the strong advantage of low-MWCNT-concentration cooling systems, especially those integrated into a limited space (e.g., electric vehicles).

\section{Conclusion}

The purpose of this study was to develop a novel heatdissipation system for dual green energy sources by using low-MWCNT-concentration CNWNFs. The conclusions and academic contributions are summarized as follows.

(1) Characterization of low-MWCNT-concentration CNWNFs: CNTs at concentrations of $0.125,0.25$, and $0.5 \mathrm{wt} . \%$, chitosan at a concentration of $0.2 \mathrm{wt} . \%$, and water were mixed using a 2-step synthesis method, and the density, viscosity, thermal conductivity, and heat capacity of the mixtures at 40,50 , and $60^{\circ} \mathrm{C}$ were measured and analyzed. 
TABLE 5: RSDs for $T_{S 1}$ and $T_{S 2}$ at three heating ratios in the cases of water and CNWNFs.

\begin{tabular}{lcccc}
\hline \multirow{2}{*}{ Temperature } & & \multicolumn{3}{c}{ Heating ratio } \\
& & $2: 8$ & $4: 6$ & $5: 5$ \\
\hline \multirow{3}{*}{$T_{S 1}$} & Water & 2.638 & 1.563 & 2.296 \\
& CNWNFs & 1.252 & 1.136 & 1.623 \\
& Enhancement & $52.5 \%$ & $27.3 \%$ & $29.3 \%$ \\
$T_{S 2}$ & Water & 1.059 & 0.984 & 1.406 \\
& CNWNFs & 0.662 & 0.793 & 0.684 \\
& Enhancement & $37.4 \%$ & $19.4 \%$ & $51.4 \%$ \\
\hline
\end{tabular}

(2) Experimental platform and mechatronics: two heat sources with a finned-tube heat exchanger and controllable key components, namely, a proportional valve, a fan system, and a coolant pump, were integrated. A microchip controller with a rule-based control strategy was designed to manage the system effectively.

(3) Steady-state performance and optimal CNT weight fraction: the pumping power and heat dissipation at 3 heating ratios $(2: 8,4: 6$, and $5: 5)$ and 2 flow rates ( 3 and $5 \mathrm{~L} / \mathrm{min}$ ) were measured. Two performance indices, the HDER and SHDER, were defined and calculated. The optimal CNT weight fraction was determined to be $0.125 \%$. The temperature stability and variations of the heat sources at distinct HFRs, heating ratios, and flow rates were measured and analyzed.

(4) Transient dynamics and stability analysis: the closedloop control of the microchip controller was used to manage the HFR and fan system effectively, thus enabling the actual temperatures of the heating sources to reach the preset target temperatures $\left(40^{\circ} \mathrm{C}\right.$ and $\left.60^{\circ} \mathrm{C}\right)$ at the 3 heating ratios tested. The temperature stability was analyzed according to the RSDs of the 2 energy sources at the 3 heating ratios. The results revealed that, when the CNWNFs were used, the heat-dissipation system controlled the target temperatures of the sources effectively and enhanced the temperature stability by an average of $36.2 \%$ compared with that observed when water was used as the coolant.

(5) A benefit analysis revealed that using the CNWNFs in the heat-dissipation system increased the system efficiency by $3 \%$ and $7 \%$ compared with water at flow rates of $3 \mathrm{~L} / \mathrm{min}$ and $5 \mathrm{~L} / \mathrm{min}$, respectively. The proposed system is expected to be integrated with real automotive hybrid green energy sources in the near future.

\section{Conflict of Interests}

The authors declare that there is no conflict of interests regarding the publication of this paper.

\section{Acknowledgment}

The authors would like to thank the National Science Council of the Republic of China for financially supporting this research under Contract nos. NSC 102-2221-E-003-018 and NSC 101-2221-E-003-014.

\section{References}

[1] J. Baker, "What are batteries, fuel cells and supercapacitors," Chemical Reviews, vol. 104, pp. 4245-4269, 2004.

[2] S. Barrett, "The European hydrogen and fuel cell strategic research agenda and deployment strategy," Fuel Cells Bulletin, vol. 2005, no. 5, pp. 12-19, 2005.

[3] G. J. Offer, D. Howey, M. Contestabile, R. Clague, and N. P. Brandon, "Comparative analysis of battery electric, hydrogen fuel cell and hybrid vehicles in a future sustainable road transport system," Energy Policy, vol. 38, no. 1, pp. 24-29, 2010.

[4] P. Thounthong, V. Chunkag, P. Sethakul, B. Davat, and M. Hinaje, "Comparative study of fuel-cell vehicle hybridization with battery or supercapacitor storage device," IEEE Transactions on Vehicular Technology, vol. 58, no. 8, pp. 3892-3904, 2009.

[5] K. T. Chau and Y. S. Wong, "Hybridization of energy sources in electric vehicles," Energy Conversion and Management, vol. 42, no. 9, pp. 1059-1069, 2001.

[6] P. Thounthong, S. Raël, and B. Davat, "Energy management of fuel cell/battery/supercapacitor hybrid power source for vehicle applications," Journal of Power Sources, vol. 193, no. 1, pp. 376385, 2009.

[7] M. Koot, J. T. B. A. Kessels, B. de Jager, W. P. M. H. Heemels, P. P. J. van den Bosch, and M. Steinbuch, "Energy management strategies for vehicular electric power systems," IEEE Transactions on Vehicular Technology, vol. 54, no. 3, pp. 771-782, 2005.

[8] J. Bauman and M. Kazerani, "A comparative study of fuelcell-battery, fuel-cell-ultracapacitor, and fuel-cell-batteryultracapacitor vehicles," IEEE Transactions on Vehicular Technology, vol. 57, no. 2, pp. 760-769, 2008.

[9] C. E. Thomas, "Fuel cell and battery electric vehicles compared," International Journal of Hydrogen Energy, vol. 34, no. 15, pp. 6005-6020, 2009.

[10] Y. Shan and S. Choe, "A high dynamic PEM fuel cell model with temperature effects," Journal of Power Sources, vol. 145, no. 1, pp. 30-39, 2005.

[11] Y. Zhang, M. Ouyang, Q. Lu, J. Luo, and X. Li, "A model predicting performance of proton exchange membrane fuel cell stack thermal systems," Applied Thermal Engineering, vol. 24, no. 4, pp. 501-513, 2004.

[12] P. Hu, G.-Y. Cao, X.-J. Zhu, and M. Hu, "Coolant circuit modeling and temperature fuzzy control of proton exchange membrane fuel cells," International Journal of Hydrogen Energy, vol. 35, no. 17, pp. 9110-9123, 2010.

[13] A. Faghri and Z. Guo, "Challenges and opportunities of thermal management issues related to fuel cell technology and modeling," International Journal of Heat and Mass Transfer, vol. 48, no. 19-20, pp. 3891-3920, 2005.

[14] M. A. Sakka, H. Gualous, J. van Mierlo, and H. Culcu, “Thermal modeling and heat management of supercapacitor modules for vehicle applications," Journal of Power Sources, vol. 194, no. 2, pp. 581-587, 2009. 
[15] J. Mottard, C. Hannay, and E. L. Winandy, "Experimental study of the thermal behavior of a water cooled Ni-Cd battery," Journal of Power Sources, vol. 117, no. 1-2, pp. 212-222, 2003.

[16] X. M. Xu and R. He, "Research on the heat dissipation performance of battery pack based on forced air cooling," Journal of Power Sources, vol. 240, pp. 33-41, 2013.

[17] H. Park, "A design of air flow configuration for cooling lithium ion battery in hybrid electric vehicles," Journal of Power Sources, vol. 239, pp. 30-36, 2013.

[18] N. Sato, "Thermal behavior analysis of lithium-ion batteries for electric and hybrid vehicles," Journal of Power Sources, vol. 99, no. 1-2, pp. 70-77, 2001.

[19] S. C. Chen, C. C. Wan, and Y. Y. Wang, "Thermal analysis of lithium-ion batteries," Journal of Power Sources, vol. 140, no. 1, pp. 111-124, 2005.

[20] Y. Hung, T.-P. Teng, and J.-H. Chen, "Assessment of heat dissipation performance for nanofluid," Applied Thermal Engineering, vol. 32, no. 1, pp. 132-140, 2012.

[21] M. J. Assael, C. F. Chen, I. Metaxa, and W. A. Wakeham, "Thermal conductivity of suspensions of carbon nanotubes in water," International Journal of Thermophysics, vol. 25, no. 4, pp. 971-985, 2004.

[22] Y. H. Hung, J. H. Chen, and T. P. Teng, "Feasibility assessment of thermal management system for green power sources using nanofluid," Journal of Nanomaterials, vol. 2013, Article ID 321261, 11 pages, 2013.

[23] M. S. Liu, M. Ching-Cheng Lin, I. T. Huang, and C. C. Wang, "Enhancement of thermal conductivity with carbon nanotube for nanofluids," International Communications in Heat and Mass Transfer, vol. 32, no. 9, pp. 1202-1210, 2005.

[24] Y. Ding, H. Alias, D. Wen, and R. A. Williams, "Heat transfer of aqueous suspensions of carbon nanotubes (CNT nanofluids)," International Journal of Heat and Mass Transfer, vol. 49, no. 1-2, pp. 240-250, 2006.

[25] R. Lotfi, A. M. Rashidi, and A. Amrollahi, "Experimental study on the heat transfer enhancement of MWNT-water nanofluid in a shell and tube heat exchanger," International Communications in Heat and Mass Transfer, vol. 39, no. 1, pp. 108-111, 2012.

[26] B. Aladag, S. Halelfadl, N. Doner, T. Maré, S. Duret, and P. Estellé, "Experimental investigations of the viscosity of nanofluids at low temperatures," Applied Energy, vol. 97, pp. 876-880, 2012.

[27] T. Maré, S. Halelfadl, O. Sow, P. Estellé, S. Duret, and F. Bazantay, "Comparison of the thermal performances of two nanofluids at low temperature in a plate heat exchanger," Experimental Thermal and Fluid Science, vol. 35, no. 8, pp. 1535-1543, 2011.

[28] Y. H. Hung and W. C. Chou, "Chitosan for suspension performance and viscousity of MWCNTs," International Journal of Chemical Engineering and Applications, vol. 3, pp. 343-346, 2012.

[29] T. P. Teng and Y. H. Hung, "Estimation and experimental study of the density and specific heat for alumina nanofluid," Journal of Experimental Nanoscience, vol. 9, no. 7, pp. 707-718, 2014.

[30] G. K. Batchelor, "The effect of Brownian motion on the bulk stress in a suspension of spherical particles," Journal of Fluid Mechanics, vol. 83, no. 1, pp. 97-117, 1977. 

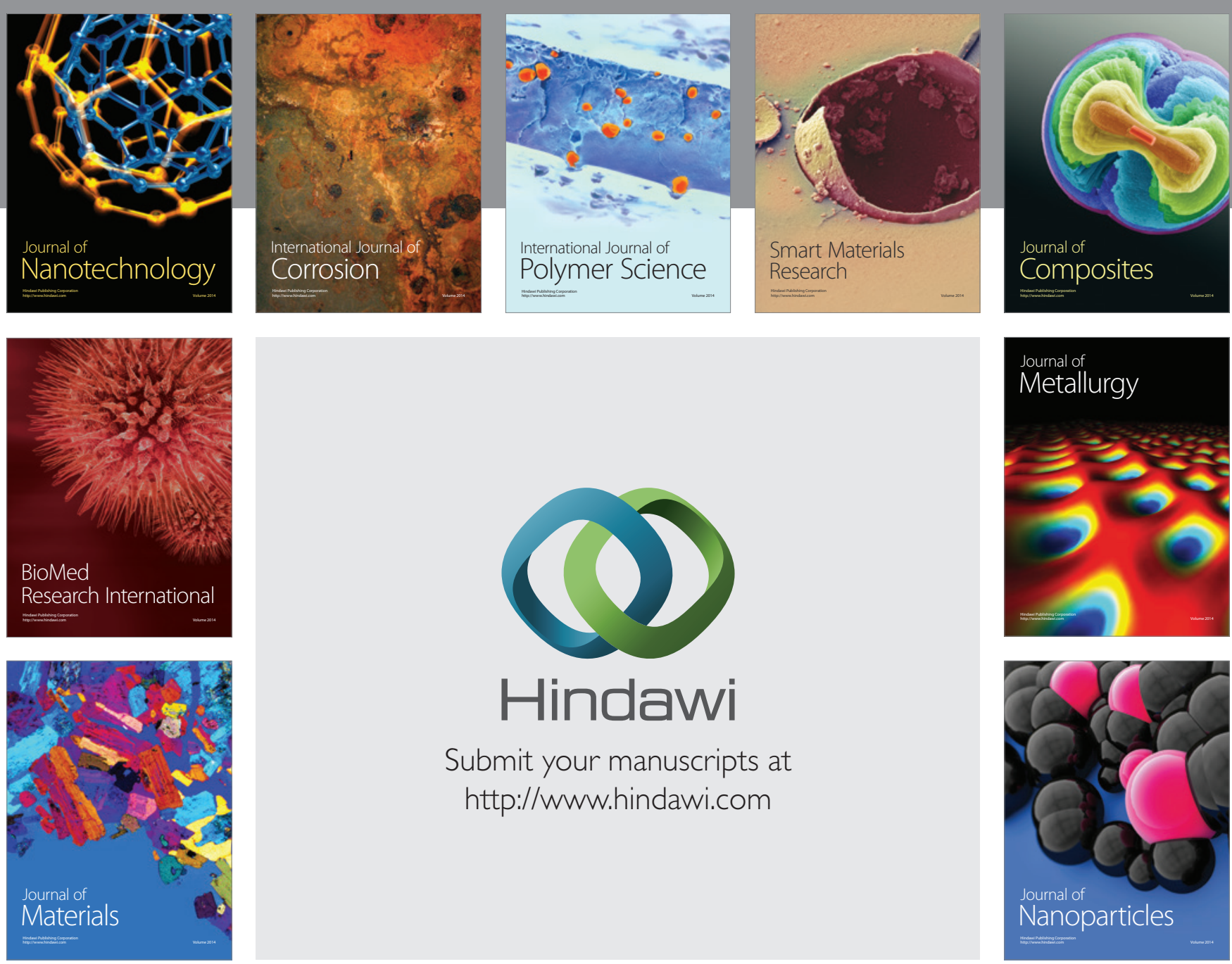

Submit your manuscripts at http://www.hindawi.com
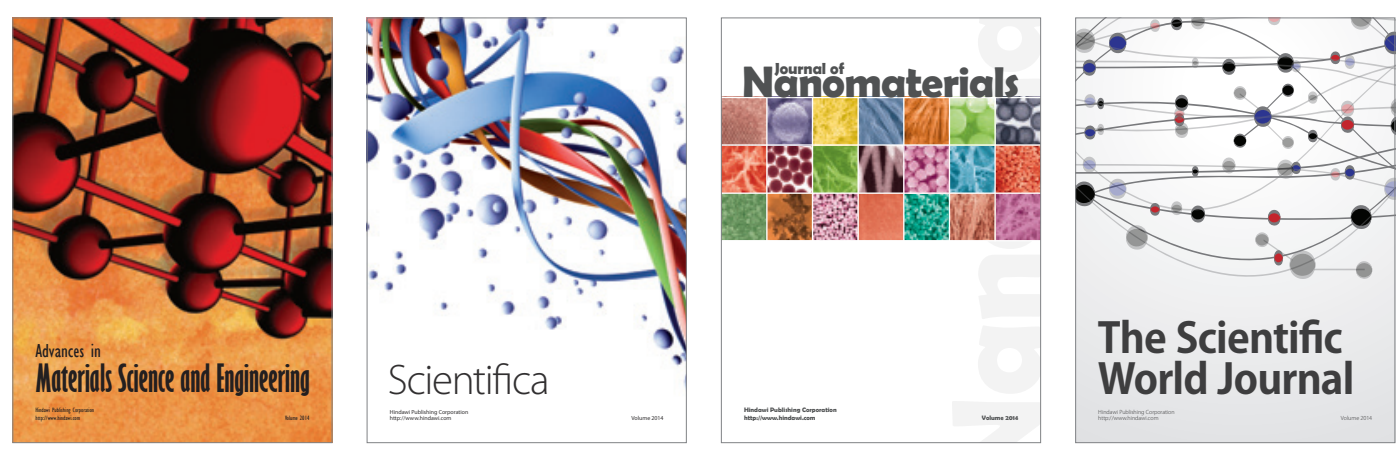

\section{The Scientific World Journal}
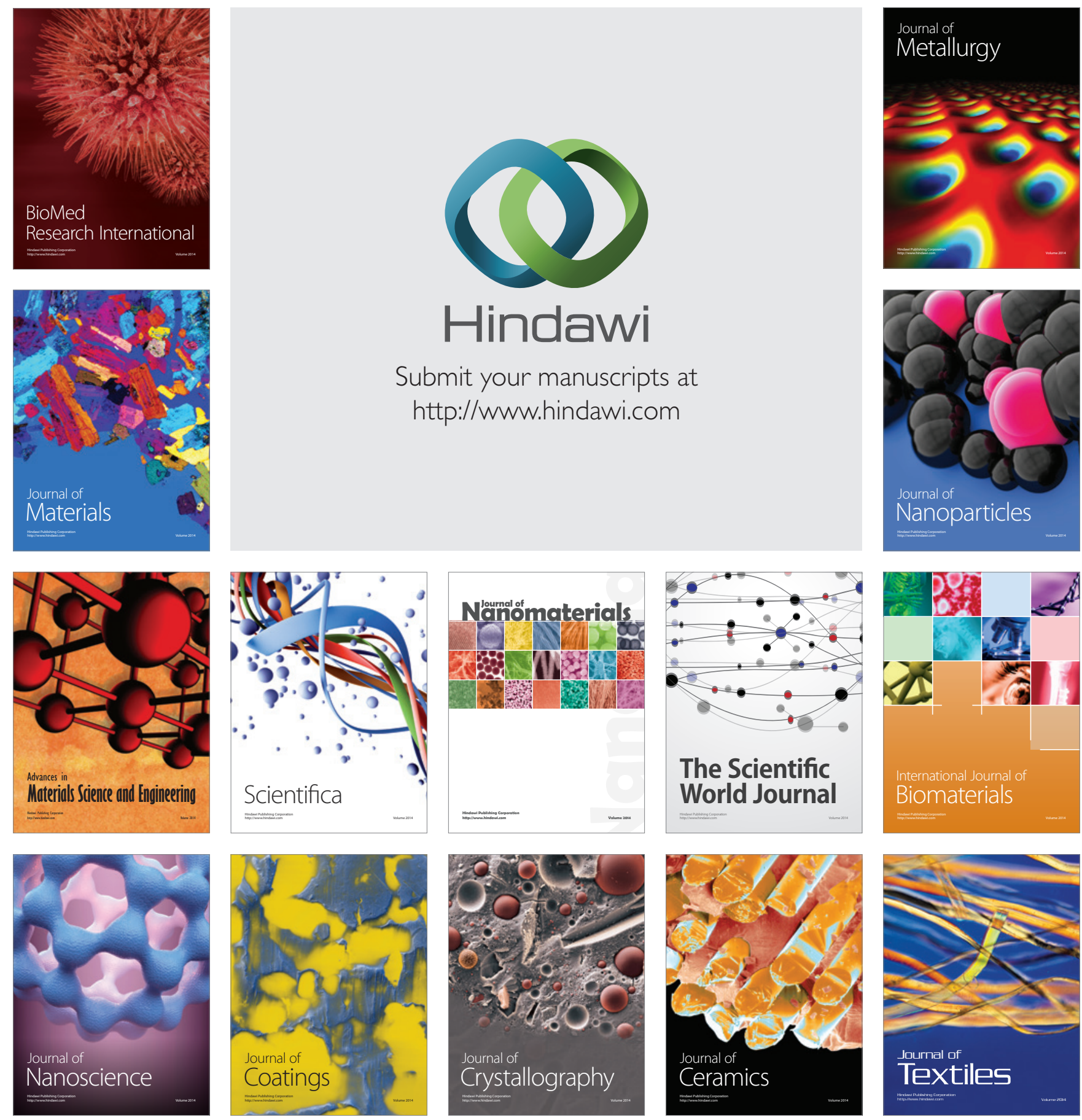